\title{
A coupled model on fluid flow, heat transfer and solidification in continuous casting mold
}

\author{
Xu-bin Zhang, Wei Chen, and *Li-feng Zhang \\ School of Metallurgical and Ecological Engineering, University of Science and Technology Beijing, Beijing 100083, China
}

\begin{abstract}
Fluid flow, heat transfer and solidification of steel in the mold are so complex but crucial, determining the surface quality of the continuous casting slab. In the current study, a 2D numerical model was established by Fluent software to simulate the fluid flow, heat transfer and solidification of the steel in the mold. The VOF model and $k-\varepsilon$ model were applied to simulate the flow field of the three phases (steel, slag and air), and solidification model was used to simulate the solidification process. The phenomena at the meniscus were also explored through interfacial tension between the liquid steel and slag as well as the mold oscillation. The model included a $20 \mathrm{~mm}$ thick mold to clarify the heat transfer and the temperature distribution of the mold. The simulation results show that the liquid steel flows as upper backflow and lower backflow in the mold, and that a small circulation forms at the meniscus. The liquid slag flows away from the corner at the meniscus or infiltrates into the gap between the mold and the shell with the mold oscillating at the negative strip stage or at the positive strip stage. The simulated pitch and the depth of oscillation marks approximate to the theoretical pitch and measured depth on the slab.
\end{abstract}

Key words: continuous casting; heat transfer; solidification; VOF model; meniscus shape; mold
CLC numbers: TP391.99
Document code: $\mathbf{A}$
Article ID: 1672-6421(2017)05-416-05

I $n$ the continuous casting process of the slab, many complex phenomena ${ }^{[1-3]}$ occur in the mold, including fluid flow, heat transfer, steel solidification, interaction between steel and $\operatorname{slag}^{[4]}$, etc. The liquid steel flows into the mold cavity through the submerged entry nozzle (SEN) and then solidifies against the four walls of the water-cooling copper mold. The solidified shell is continuously withdrawn downward at the casting speed. The slag powder is continuously added on the top of the steel, then melts or sinters to form a slag bed, and liquid slag infiltrates into the gap between the shell and the mold ${ }^{[5,6]}$. Due to the interfacial tension, a curved meniscus ${ }^{[7]}$ forms between liquid steel and liquid slag, and solidifies with the heat transfer from the steel to the mold. Heat transfer and solidification of the liquid steel at the meniscus as well as the mold oscillation affect the formation of the oscillation marks ${ }^{[8]}$, which may cause some defects in the slab, including slag entrapment ${ }^{[9]}$, bubble and inclusion capture, element segregation, transverse cracks ${ }^{[10]}$, etc.

In the current study, a 2D model was established to simulate the multiphase fluid flow of steel-slag-

\footnotetext{
* Li-feng Zhang

Male, born in 1972, Professor. His research interests mainly focus on numerical simulation in metallurgical process and non-metallic inclusions in steel.

E-mail: zhanglifeng@ustb.edu.cn
}

Received: 2017-08-15; Accepted: 2017-09-15 air, heat transfer and solidification in the mold with mold oscillation. The model considered the interfacial tension between different phases and shell movement at the casting speed. The phase distribution and flow field in the mold were simulated, and phenomena near the meniscus were presented, including meniscus solidification, slag penetration and movement of the mold and the shell. The comparison of simulated pitch and depth of oscillation marks with theoretical pitch and measured depth on the slab surface was conducted to validate the accuracy of the simulation.

\section{Model description}

\subsection{Governing equations}

The model developed in the study couples a multiphase steel-slag-air flow approach with heat transfer, mold oscillation and solidification in the mold during continuous casting of steel slabs. The model is based on the commercial software ANSYS-Fluent 14.0, and solves the Navier-Stokes equations ${ }^{[11]}$ coupled with the volume of fluid (VOF) method for calculation of phase fractions and the continuum surface force (CFS) method for tracking the steel-slag-air interfaces. The $k-\varepsilon$ viscous model and the standard wall functions are used to account for the turbulence in the system. The energy equation and Fourier equation are solved, and the solidification model is applied to consider the heat 
transfer and solidification in the mold.

In the VOF scheme, the effective density $\left(\rho_{\text {mix }}, \mathrm{kg} \cdot \mathrm{m}^{-3}\right)$ and the effective viscosity $\left(\mu_{\text {mix }}, \mathrm{kg} \cdot \mathrm{m}^{-1} \cdot \mathrm{s}^{-1}\right)$ are given by:

$$
\begin{aligned}
& \rho_{\text {mix }}=\alpha_{\mathrm{p}} \rho_{\mathrm{p}}+\left(1-\alpha_{\mathrm{p}}\right) \rho_{\mathrm{q}} \\
& \mu_{\text {mix }}=\alpha_{\mathrm{p}} \mu_{\mathrm{p}}+\left(1-\alpha_{\mathrm{p}}\right) \mu_{\mathrm{q}}
\end{aligned}
$$

where $\alpha$ is the phase fraction and the subscripts $\mathrm{p}$ and $\mathrm{q}$ represent any two of the three phases present in the cell (steel, slag or air). Thus, the continuity equation for the volume fraction of any of the phases can be derived by:

$$
\frac{\partial}{\partial t}\left(\alpha_{\mathrm{q}} \rho_{\mathrm{q}}\right)+\nabla \cdot\left(\alpha_{\mathrm{q}} \rho_{\mathrm{q}} \vec{v}\right)=\sum_{p=1}^{n}\left(\dot{m}_{\mathrm{pq}}-\dot{m}_{\mathrm{qp}}\right)
$$

where $\vec{v}$ is the overall velocity vector $\left(\mathrm{m} \cdot \mathrm{s}^{-1}\right), \dot{m}_{\mathrm{pq}}$ is the mass transfer from phase $\mathrm{p}$ to phase $\mathrm{q}\left(\mathrm{kg} \cdot \mathrm{s}^{-1}\right), \dot{m}_{\mathrm{qp}}$ is the mass transfer from phase $\mathrm{q}$ to phase $\mathrm{p}\left(\mathrm{kg} \cdot \mathrm{s}^{-1}\right)$. The volume fraction for the primary phase is computed based on the following constraint:

$$
\sum_{p=1}^{n}\left(\alpha_{\mathrm{q}}\right)=1
$$

Energy equation for fluid:

$$
\begin{gathered}
\frac{\partial}{\partial t}\left(\rho_{\text {mix }} E\right)+\nabla \cdot\left(\vec{v}\left(\rho_{\text {mix }} E+P\right)\right)=\nabla \cdot\left(K_{\text {eff }} \nabla T+\left(\tau_{\text {eff }} \cdot \vec{v}\right)\right) \\
E=\frac{\sum_{q=1}^{n}\left(\alpha_{\mathrm{q}} \rho_{\mathrm{q}} E_{\mathrm{q}}\right)}{\sum_{q=1}^{n}\left(\alpha_{\mathrm{q}} \rho_{\mathrm{q}}\right)}
\end{gathered}
$$

where $E$ is the enthalpy ( $\mathrm{J}), K_{\text {eff }}$ is the effective thermal conductivity $\left(\mathrm{W} \cdot \mathrm{m}^{-1} \cdot \mathrm{K}^{-1}\right), E_{\mathrm{q}}$ depends on the specific heat for the q phase.

Heat conduction for solid:

$$
\frac{\partial}{\partial t}(\rho h)=\nabla \cdot\left(K_{\mathrm{m}} \nabla T\right)
$$

where $h$ is the sensible enthalpy ( $\mathrm{J})$ and $K_{\mathrm{m}}$ is the effective thermal conductivity $\left(\mathrm{W} \cdot \mathrm{m}^{-1} \cdot \mathrm{K}^{-1}\right)$.

\subsection{Model domains and simulation conditions}

The 2D domain consists of half SEN, half slab mold, copper plate and $0.5 \mathrm{~m}$ of slab length after the mold exit. The mesh of 2D mold is exhibited in Fig.1(a). Due to the simulation of an initial solidification and oscillation mark with the size of $0.2-$ $0.5 \mathrm{~mm}$, the refined mesh locates at the interface of steel and slag, especially at the meniscus near the corner. The minimum size of the cell is $50 \mu \mathrm{m}$, and the total cell number is 151,934 . In order to investigate the formation of a curved meniscus and the slag infiltration between the shell and mold, the slag of $50 \mathrm{~mm}$ thickness is considered on the top of the steel in the mold, and the interfacial tension and contact angle between liquid steel and liquid slag is set as $1.3 \mathrm{~N} \cdot \mathrm{m}^{-1}$ and $46^{\circ}$, respectively. The dynamic mesh is applied to the mold, and the mold oscillates with the frequency of 182 cycles per minute (cpm). The expressions for determining the mold position and mold velocity are as follows:

$$
\begin{aligned}
s & =A \sin \left(\frac{2 \pi f}{60} t\right) \\
v_{\mathrm{m}} & =\frac{2 \pi f}{60} A \cos \left(\frac{2 \pi f}{60} t\right)
\end{aligned}
$$

where $s$ is mold position (m), $A$ is oscillation amplitude of the mold $(\mathrm{m}), f$ is oscillation frequency $(\mathrm{cpm})$ and $v_{\mathrm{m}}$ is mold velocity $\left(\mathrm{m} \cdot \mathrm{s}^{-1}\right)$.

The model considers the interaction among three phases of steel, slag and air, and the material parameters are exhibited in Table 1. The solidification of the steel is considered, and the solidification coefficient is set as $5 \times 10^{8}$. The thermal conductivity of steel has a relation to the steel temperature. After the steel solidification, the casting speed of $1.45 \mathrm{~m} \cdot \mathrm{min}^{-1}$ is applied to the solidified shell. In case of the application of the casting speed to the solidified slag, the model neglects the formation of the solidified slag. However, the viscosity and thermal conductivity of liquid slag are related to the temperature, and the liquid slag has the same property as the solidified slag when the temperature is lower than the break temperature of the $\operatorname{slag}^{[12]}$. The model can therefore predict the movement and heat

Table 1: Material parameters

\begin{tabular}{ll} 
Parameter & Value \\
\hline Density of liquid steel, $\rho_{\text {steel }}\left(\mathrm{kg} \cdot \mathrm{m}^{-3}\right)$ & 7,020 \\
Viscosity of liquid steel, $\mu_{\text {steel }}\left(\mathrm{kg} \cdot \mathrm{m}^{-1} \cdot \mathrm{s}^{-1}\right)$ & 0.0063 \\
Specific heat of steel, $C_{\mathrm{p} \text {, steel }}\left(\mathrm{J} \cdot \mathrm{kg}^{-1} \cdot \mathrm{K}^{-1}\right)$ & 750 \\
Latent heat of steel, $H_{\mathrm{steel}}\left(\mathrm{J} \cdot \mathrm{kg}^{-1}\right)$ & 270,000 \\
Liquidus of steel, $T_{\mathrm{L}}(\mathrm{K})$ & 1,805 \\
Solidus of steel, $T_{\mathrm{s}}(\mathrm{K})$ & 1,790 \\
Density of liquid $\mathrm{slag}, \rho_{\mathrm{slag}}\left(\mathrm{kg} \cdot \mathrm{m}^{-3}\right)$ & 2,500 \\
Specific heat of $\mathrm{slag}, C_{\mathrm{p}, \text { slag }}\left(\mathrm{J} \cdot \mathrm{kg}{ }^{-1} \cdot \mathrm{K}^{-1}\right)$ & 830 \\
Air density, $\rho_{\text {air }}\left(\mathrm{kg} \cdot \mathrm{m}^{-3}\right)$ & 1.225 \\
Air viscosity, $\mu_{\text {air }}\left(\mathrm{kg} \cdot \mathrm{m}^{-1} \cdot \mathrm{s}^{-1}\right)$ & $1.8 \times 10^{-5}$ \\
Interfacial tension of slag-steel, $\gamma\left(\mathrm{N} \cdot \mathrm{m}^{-1}\right)$ & $1.3^{[10]}$
\end{tabular}

transfer of the slag.

The simulation conditions are shown in Fig. 1(b). The initial temperatures of the fluids (steel, slag and air) and the mold are $1,805 \mathrm{~K}$ and $405 \mathrm{~K}$, respectively. The thickness of the slag and air at the top of the mold are both $50 \mathrm{~mm}$, and the thickness of the copper mold is $20 \mathrm{~mm}$. The conditions of velocity inlet and outflow are applied to the nozzle top and the outlet at the model bottom, respectively. The temperature at the mold top is considered as room temperature $(300 \mathrm{~K})$, the heat transfer coefficients ${ }^{[13]}$ on the cold face $\left(h_{\mathrm{c}}\right)$ of the mold and the side face of the steel below the mold $\left(h_{\mathrm{s}}\right)$ are calculated from the cooling water flow of the plant. The detailed simulation parameters are shown in Table 2. Since the multiphase fluid flow, heat transfer and solidification with the mold oscillation are considered through the $2 \mathrm{D}$ model, and the refined mesh is used, the simulation is time-consuming. With the time step of $0.00001 \mathrm{~s}$ and six eight-core computers, the calculation time every day can be about $0.5 \mathrm{~s}$, and the results are calculated for several weeks.

\section{Results and discussion}

The phase distribution, streamlines and velocity contour are 
(a)

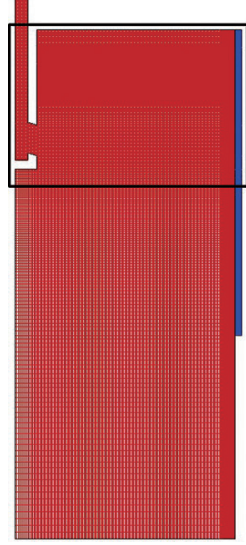

(b)

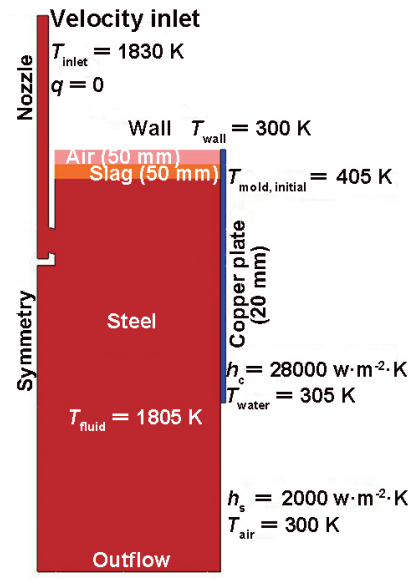

Fig. 1: Model mesh (a) and simulation conditions (b) of 2D model

Table 2: Simulation parameters

\begin{tabular}{ll} 
Parameter & Value / Type \\
\hline Mold width $(\mathrm{mm})$ & 1,300 \\
Mold length $(\mathrm{mm})$ & 1,000 \\
Simulation length $(\mathrm{mm})$ & 1,500 \\
Slag thickness $(\mathrm{mm})$ & 50 \\
Air thickness $(\mathrm{mm})$ & 50 \\
Mold thickness $(\mathrm{mm})$ & 20 \\
Mold oscillation mode & Sinusoidal \\
Oscillation frequency, $f(\mathrm{cpm})$ & 182 \\
Oscillation stroke, $s_{\mathrm{osc}}(\mathrm{mm})$ & 6 \\
Casting temperature, $T_{\mathrm{p}}(\mathrm{K})$ & 1,830 \\
Casting speed, $v_{\mathrm{c}}\left(\mathrm{m} \cdot \mathrm{min}^{-1}\right)$ & 1.45
\end{tabular}

illustrated in Fig. 2. The liquid steel out of the SEN flows as the upper backflow and lower backflow, and the velocity of the backflows are $0.4-0.8 \mathrm{~m} \cdot \mathrm{s}^{-1}$ and $0.5-1.1 \mathrm{~m} \cdot \mathrm{s}^{-1}$. Due to the upper backflow flowing to the nozzle, the steel level near the mold is

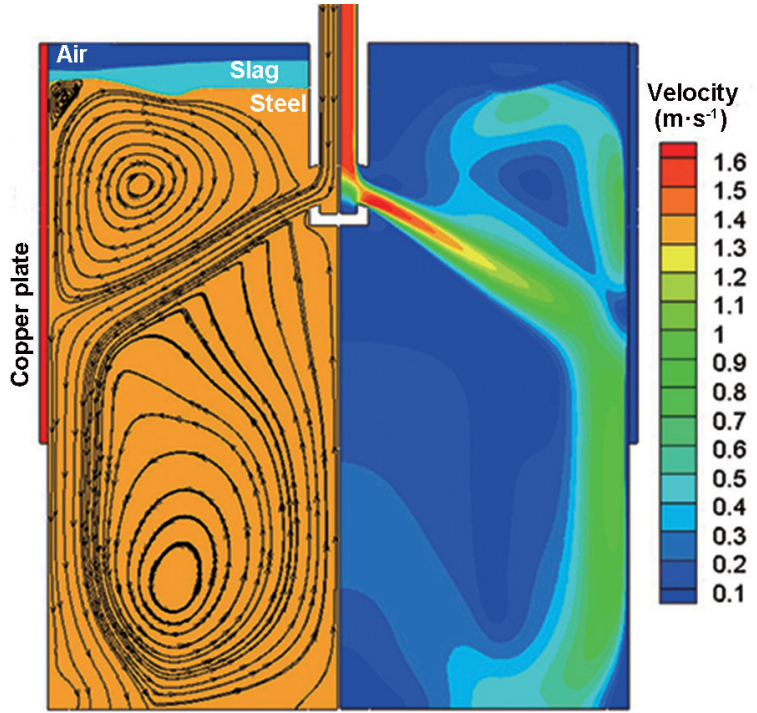

Fig. 2: Phase distribution, streamlines and velocity contour higher than the one near the nozzle, and the thickness of the slag bed near the nozzle is also greater. At the center of the half mold, the liquid slag depresses the steel level, and due to the washing of the liquid steel with high speed, slag entrapment may occur. A small circulation flowing to the steel-slag interface exists at the meniscus, and the velocity of the fluid there is lower than $0.2 \mathrm{~m} \cdot \mathrm{s}^{-1}$. The circulation may be affected by natural convection, mold oscillation and pressure from the slag pool ${ }^{[6]}$.

In Fig. 3, the two curves represent the mold position $\left(m_{\text {disp }}\right)$ and velocity $\left(V_{\mathrm{m}}\right)$, respectively, the horizontal line represents the casting speed $\left(V_{\mathrm{c}}\right)$, and the positions of the points a-d in the curve are corresponding to the simulation results. The calculated temperatures of steel and mold at four oscillation speeds $(a-d)$ of the mold are demonstrated. The negative stage $\left(t_{\mathrm{n}}\right)$ as the gray part in the curve zone is between point $\mathrm{b}$ and $\mathrm{c}$, which represents the beginning and end of the negative stage, respectively. In Fig. 3(a), with the mold oscillating upward, the liquid slag infiltrates into the gap between the shell and the mold, which may be caused by the reduced pressure of the slag pool at the meniscus ${ }^{[8]}$. With the cooling of the water in the mold, the meniscus begins to solidify, and the mushy zone between the temperatures of liquidus $(1,805 \mathrm{~K})$ and solidus $(1,790 \mathrm{~K})$ appears.

From point a to point $b$ (positive strip stage), the mold oscillates upward (Fig. 3a) and then downward (Fig. 3b), the meniscus moves to the mold, and the speed of the liquid slag flowing into the gap decreases. From point $\mathrm{b}$ to point $\mathrm{c}$ (negative strip stage), the speed of the mold oscillating downward exceeds the casting speed, then the slag flows into the gap and the meniscus moves away from the mold (Fig. 3c), which may be caused by the growing pressure of the slag pool ${ }^{[8]}$. Due to the movement downward and heat transfer of the cooling mold, the meniscus solidifies more quickly. From point $\mathrm{c}$ to point $\mathrm{d}$ (positive strip stage), with the mold oscillating from downward to upward and the solidified shell moving at the casting speed, the meniscus moves to the mold (Fig. 3d) and the oscillation mark forms. Then the new meniscus solidifies again. The cycle is repeated and periodic oscillation marks form.

The distribution of practical and simulated oscillation marks with the same casting parameters in Table 1 is illustrated in 


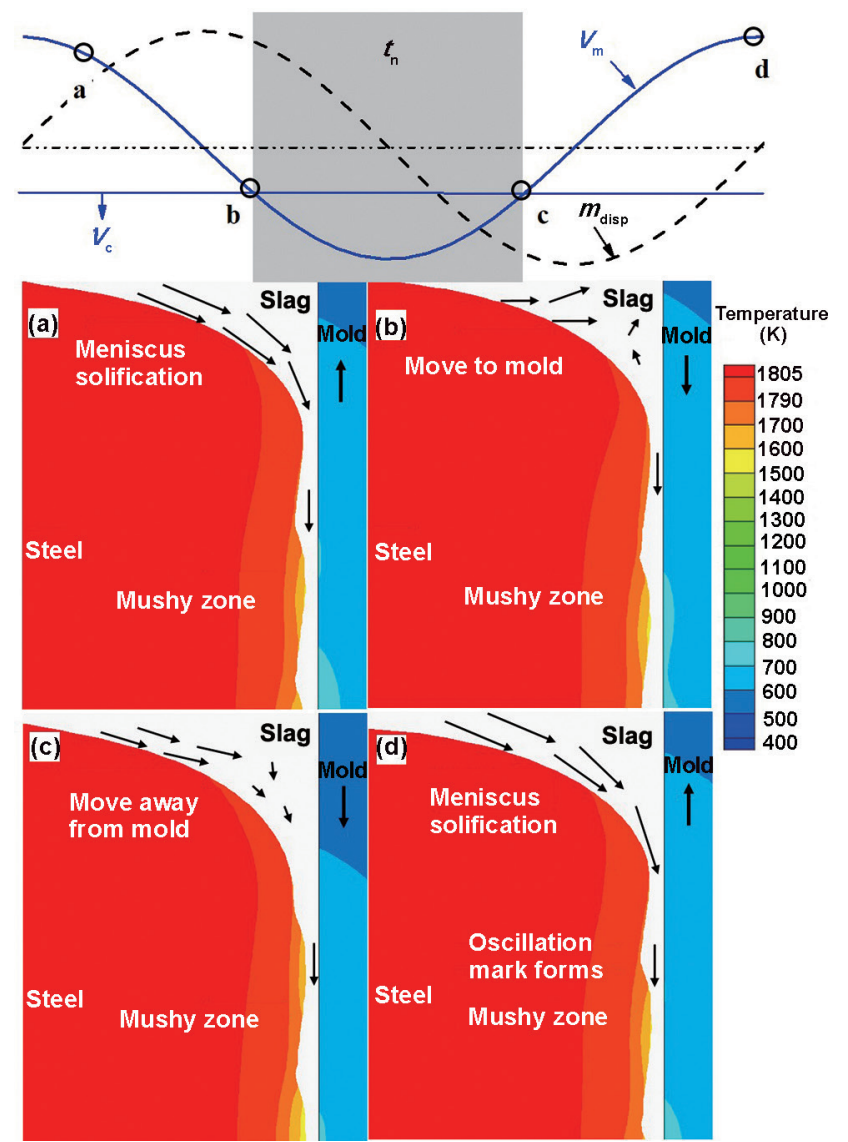

Fig. 3: Temperatures of steel and mold during one cycle

Fig. 4. Figure 4(a) shows two adjacent oscillation marks on the longitudinal section vertical to slab surface, and the slab sample including the oscillation marks was low-carbon steel (content of carbon was $0.03 \mathrm{wt} . \%$ ), and cast at the casting speed of 1.45 $\mathrm{m} \cdot \mathrm{min}^{-1}$ and the casting temperature of $1,883 \mathrm{~K}$, with the mold oscillation of $182 \mathrm{cpm}(f)$ and $6 \mathrm{~mm}\left(s_{\text {osc }}\right)$. The sample was taken from the narrow face of the slab, and the details of sample taken were introduced in literature ${ }^{[15]}$. Figure 4(b) exhibits the distribution of simulated ones. The depression length of the simulated oscillation marks is larger than that of practical ones, because the simulation does not consider the strength of
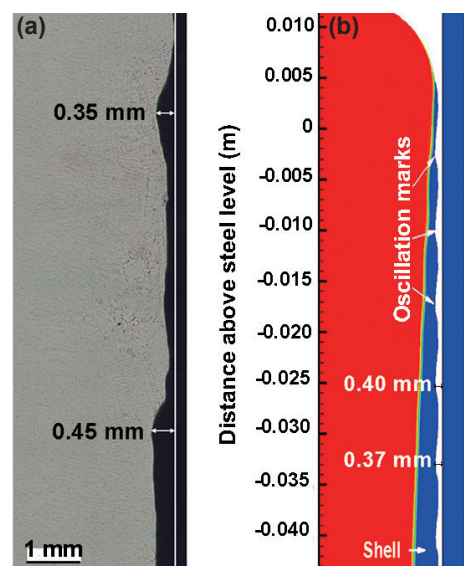

Fig. 4: Distribution of oscillation marks, (a) practical ones; (b) simulated ones the solidified shell, and the oscillation marks are depressiontypes. According to the oscillation frequency $(182 \mathrm{cpm})$ and casting speed $\left(1.45 \mathrm{~m} \cdot \mathrm{min}^{-1}\right)$, the theoretical oscillation pitch is $7.97 \mathrm{~mm}$, while after measuring the simulated oscillation mark spacing, the average is $7.66 \mathrm{~mm}$. The oscillation depth measured from the slab samples is $0.2-0.5 \mathrm{~mm}$ and the average is 0.299 $\mathrm{mm}$, while the simulated oscillation depth is $0.3-0.5 \mathrm{~mm}$ and the average is $0.384 \mathrm{~mm}$. Therefore the simulation in the study can explain the phenomena occurred at the meniscus and the formation of oscillation marks.

\section{Conclusion}

In the current study, a 2D model was established to simulate the multiphase fluid flow of steel-slag-air, heat transfer and solidification in the mold with the mold oscillation. The conclusions are as follows:

(1) In the mold, the liquid steel flows as upper backflow and lower backflow, and the small circulation forms at the meniscus. The upper backflow can increase the risk of slag entrapment.

(2) At the positive strip stage, the mold moves upwards with respect to the mold, and the slag infiltrates into the gap between the shell and the mold as lubricant. At the negative strip stage, the mold moves downwards relative to the mold, and the slag flows out of the gap. With the cooling of the mold with a lower temperature, the meniscus solidifies further, and then deeper oscillation marks may form.

(3) The simulated pitch and depth of oscillation marks approximate to the theoretical pitch and measured depth from the slab samples, respectively. Therefore, the simulation in the study can explain the phenomena occurred at the meniscus and the formation of oscillation marks.

\section{References}

[1] Lee P, Ramirezlopez P, Mills K, et al. Review: The "butterfly effect" in continuous casting. Ironmaking \& Steelmaking, 2012, (4): 244-253.

[2] Thomas B G. Continuous Casting of Steel. Chapter 15, 2001 : 499-540.

[3] Mizoguchi S, Ohashi T, Saeki T. Continuous casting of steel. Annual Review of Materials Science, 1981, 11 (1): 151-169.

[4] Mills K, Ramirezlopez P, Lee P, et al. Looking into continuous casting mould. Ironmaking \& Steelmaking, 2014, 41 (4): 242249.

[5] Mills K, Fox A, Li Z, et al. Performance and properties of mould fluxes. Ironmaking \& Steelmaking, 2005, 32 (1): 26-34.

[6] Ramirez Lopez P, Sjöström U, Lee P, et al. A Novel Approach for Coupling Slag Infiltration to Metal Flow, Solidification and Mold Oscillation on a 3D Model for Continuous Casting of Slabs. In: Proc. Iron \& Steel Technology Conference and Exposition, Aistech, 2012.

[7] Sengupta J, Thomas B G, Shin H, et al. A new mechanism of hook formation during continuous casting of ultra-low-carbon steel slabs. Metallurgical and Materials Transactions A, 2006, 37 (5): 1597-1611.

[8] Ramirez Lopez P, Mills K, Lee P, et al. A unified mechanism for 
the formation of oscillation marks. Metallurgical and Materials Transactions B, 2012, 43 (1): 109-122.

[9] Hibbeler L, Thomas B G. Mold slag entrainment mechanisms in continuous casting molds. Iron and Steel Technology, 2013, 10 (10): 121-136.

[10] Harada S, Tanaka S, Misumi H, et al. A formation mechanism of transverse cracks on CC slab surface. ISIJ International, 1990, 30 (4): 310-316.

[11] Jonayat A, Thomas B G. Transient thermo-fluid model of meniscus behavior and slag consumption in steel continuous casting. Metallurgical \& Materials Transactions B, 2014, 45 (5): 1842-1864.
[12] Meng Y, Thomas B G. Modeling transient slag-layer phenomena in the shell/mold gap in continuous casting of steel. Metallurgical and Materials Transactions B, 2003, 34 (5): 707-725.

[13] Ramirez Lopez P. Modelling shell and oscillation mark formation during continuous casting via explicit incorporation of slag infiltration. Imperial College London, 2010.

[14] Ojeda C, Thomas B G, Barco J, et al. Model of thermal-fluid flow in the meniscus region during an oscillation cycle. In: Proc. AISTech, 2007, 2: 269-283.

[15] Zhang $X$, Zhang $L$, Wang $H$, et al. Subsurface hooks in continuous casting slabs of low-carbon steel. Chinese Journal of Engineering, 2017, 39 (2): 251-258.

This work was financially supported by the National Natural Science Foundation of China (No. 51504020, and No. 51404019), Beijing Key Laboratory of Green Recycling and Extraction of Metals (GREM), the Laboratory of Green Process Metallurgy and Modeling (GPM2) and the High Quality Steel Consortium (HQSC) at the School of Metallurgical and Ecological Engineering at University of Science and Technology Beijing (USTB), China 